\title{
Intravenous isotonic fluid challenge, and L-arginine infusion for oligoamnios and diminished fetal movements: a preliminary study
}

\author{
Samartha Ram Hemmanur ${ }^{1 *}$, Illa Sai Samyuktha ${ }^{3}$, Nagashree Vasudeva ${ }^{2}$
}

\author{
${ }^{1}$ Department of Obstetrics and Gynecology, ${ }^{2}$ Junior Resident, Sandhyaram Maternity Hospital, Katampazhi Puram, \\ Palakkad, Kerala, India \\ ${ }^{3}$ Department of Obstetrics and Gynecology, Divya Hospital, Palladam Road, Thirpur, Tamil Nadu, India
}

Received: 28 March 2021

Revised: 25 May 2021

Accepted: 27 May 2021

\section{*Correspondence:}

Dr. Samartha Ram Hemmanur,

E-mail: drsamartharam@gmail.com

Copyright: () the author(s), publisher and licensee Medip Academy. This is an open-access article distributed under the terms of the Creative Commons Attribution Non-Commercial License, which permits unrestricted non-commercial use, distribution, and reproduction in any medium, provided the original work is properly cited.

\section{ABSTRACT}

Background: Utero-placental insufficiency is one of the major causes of oligoamnios and diminished fetal movements (FM). Rapid intravenous isotonic fluid infusion within the cardiovascular reserve improves tissue perfusion in all systems. We tested the hypothesis that isotonic fluid challenge may improve uteroplacental perfusion, which may, in turn improve fetal oxygenation, liquor formation, and FM.

Methods: In this descriptive study, twenty-three antenatal mothers with gestational age $>26$ weeks, and with amniotic fluid index (AFI) $<8 \mathrm{~cm}$ were included. Intravenous isotonic fluid challenge with 2 or 3 pints of ringer's lactate, at the rate of 180-200 drops/minute, twice daily for 2-3 days, and L-arginine infusion of $300 \mathrm{ml} /$ day, on alternate days for 23 doses were given. Women were advised to take more than 3 litres of water a day. AFI was recorded once daily for 5 days, and then biweekly. The fluid challenge was repeated whenever AFI diminished $<8.00 \mathrm{~cm}$. AFI and perceived FM were graded. Pregnancies were terminated when there was no response to fluid challenge. The trend of changes in AFI and FM grades, number of days that pregnancies could be continued, and perinatal outcomes were recorded.

Results: We noted recurrent fall in AFI after an initial arise in 20 women, which required recurrent fluid challenges. Pregnancies could be continued for $18 \pm 8.5$ days (median \pm SD). Three women with absent FM, reported FM within one hour after initiation of fluid challenge. There were no perinatal deaths.

Conclusions: Intravenous isotonic fluid challenge and L-arginine infusion, improves AFI and FM, and helps to prolong pregnancies towards viability.

Keywords: Diminished fetal movements, Intravenous isotonic fluid challenge, L-arginine infusion, Oligoamnios

\section{INTRODUCTION}

Oligohydramnios, a reduction in amniotic fluid index (AFI) $<5 \mathrm{~cm}$, or a deficiency of amniotic fluid volume below the $10^{\text {th }}$ percentile of corresponding gestational age, occur in $0.8-5.5 \%$ of all pregnancies. ${ }^{1,2}$ Amniotic fluid is essential for the development of fetal lungs, musculoskeletal system, and also to prevent umbilical cord compression. ${ }^{3}$ Increased perinatal morbidity and mortality with oligohydramnios is due to diminished fetal movements, cord compression, fetal distress, low APGAR scores, and meconium aspiration syndrome. ${ }^{4-6}$

The exact cause for oligohydramnios is unknown in about $52 \%$ of the cases. ${ }^{7}$ Though congenital malformations like renal hypoplasia or agenesis, and oesophagal atresia can lead to a reduction in liquor, uteroplacental insufficiency is the major cause. ${ }^{4,5,8}$ In some women, the reduction of liquor is so rapid, that the liquor may get dried up overnight. ${ }^{9}$ Scanty liquor can occur at any gestational age of pregnancy. 
The results of per abdominal amnio-infusion (saline infusion into amniotic sac) for oligoamnios are not encouraging. ${ }^{10}$ Though this technique helps to prevent the cord compression, it cannot address diminished uteroplacental perfusion. The only definitive treatment to prevent the deleterious effects of diminished uteroplacental perfusion is to deliver the babies and then manage them in neonatal intensive care units.

Rapid intravenous isotonic fluid infusion within the cardiovascular reserve results in improved tissue perfusion in all systems. ${ }^{11}$ Samartharam et al reported that a distressed fetus during labour could be resuscitated by low dose isoxsuprine hydrochloride rapid infusion tocolysis (https://youtu.be/1vug4rtD14s). ${ }^{12}$

\section{Hypothesis}

In this study, we tested the hypothesis, "rapid intravenous isotonic fluid infusion within the cardiovascular reserve, improves blood volume and cardiac output". This results in improved tissue perfusion in all systems. Improved uteroplacental perfusion results in improved fetal oxygenation, liquor formation, and fetal movements.

\section{METHODS}

This descriptive interventional study was conducted at Sandhyaram Maternity Hospital, Katampazhipuram, Palghat, Kerala from March 20019 to February 2021.

\section{Inclusion criteria}

Twenty-three antenatal mothers with gestational age more than 26 weeks, and with AFI less than $8 \mathrm{~cm}$ were included.

\section{Exclusion criteria}

Women with congenital fetal anomalies and premature rupture of membrane (PROM) were excluded.

Informed and written consent was obtained from all the subjects who participated in this study. This study confined to the standards of declarations of Helsinki. All of them underwent USG scanning on day 1 and repeat scanning was done as and when necessary. Intravenous isotonic fluid challenge with 2 to 3 pints (depending on body weight) of ringer lactate, at the rate of 180-200 drops/minute, twice daily for 2 to 3 days was given. Larginine infusion, $300 \mathrm{ml} /$ day was given slowly (40-50 drops/minute), on alternate days for two or 3 days depending AFI response. Women were advised to take more than 3 litres of water a day. Fluid challenge was repeated when the AFI diminished $<8.00 \mathrm{~cm}$. AFI was recorded once daily for 5 days, and then biweekly. AFI was graded as follows: Grade 1: AFI $<8.00 \mathrm{~cm}$, Grade 2: $8.00-12.00 \mathrm{~cm}$, and Grade 3: $>12.00 \mathrm{~cm}$.
As per the hospital policy, all mothers recorded fetal movements by DFMC (daily fetal movement monitoring) charts from 24 weeks of GA onwards. ${ }^{12}$ Foetal kicks, as perceived by the mothers, were subjectively graded for comparison: Grade 1 kicks- occasional feeble kicks, or no kicks (diminished FM), grade 2 kicks- less powerful kicks (good FM), grade 3 kicks- brisk and powerful kicks (very good FM). These kick grades were noted at the time of every scanning for AFI.

The trend of AFI changes and FM grades in each woman were plotted in graphs (Figures 1 and 2). Antenatal corticosteroids were given whenever needed. We recorded, the number of days pregnancies could be continued, birth weight, NICU admission days, and perinatal outcomes.

\section{Statistical analysis}

Statistical software MS Excel, SPSS version 22 (IBM SPSS Statistics, Somers NY, USA) was used to analyse data. Categorical data was represented in the form of Frequencies and proportions. Chi-square test or Fischer's exact test (for $2 \times 2$ tables only) was used as a test of significance for qualitative data. Continuous data was represented as mean $\pm \mathrm{SD}$ and median $\pm \mathrm{SD}$.

\section{RESULTS}

The maternal age among 23 women who participated in this study ranged from 19 years to 37 years with a mean value of $26.21 \pm 5.06$. The frequency distribution of the gravida is as shown in the table below (Table 1). The gestational age at which therapy initiated ranged from 27 weeks \pm 2 days to 38 weeks \pm 4 days.

Table 1: Frequency distribution of the gravida.

\begin{tabular}{|l|l|}
\hline Gravida & Frequency \\
\hline $\mathbf{1}$ & 9 \\
\hline $\mathbf{2}$ & 10 \\
\hline $\mathbf{3}$ & 4 \\
\hline $\mathbf{4}$ & 1 \\
\hline
\end{tabular}

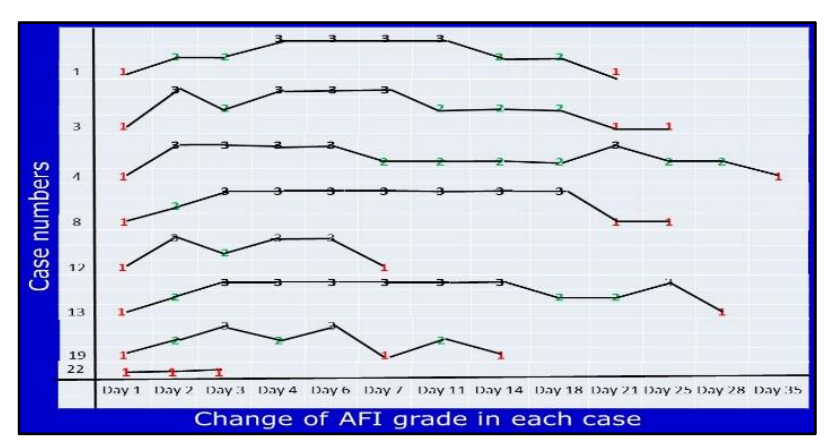

Figure 1: The trend of change in AFI Grades in selected cases.

AFI $<8.00 \mathrm{~cm}$ is grade 1; AFI between 8.01 to $12.00 \mathrm{~cm}$ is grade 2 ; AFI $>12.01 \mathrm{~cm}$ is grade 3 . 
Table 2: Number of different grades of AFI on different days of study.

\begin{tabular}{|llllll}
\hline On day & Delivered & $\mathbf{N}$ & Grade $\mathbf{1}$ AFI $<\mathbf{8 . 0 0} \mathbf{c m}$ & $\begin{array}{l}\text { Grade 2 AFI } \\
\text { AFI:8.01-12.00 } \mathbf{c m}\end{array}$ & $\begin{array}{l}\text { Grade } \mathbf{3} \text { AFI } \\
>\mathbf{1 2 . 0 0} \mathbf{c m}\end{array}$ \\
\hline $\mathbf{1}$ & 0 & 23 & $23 / 23(100 \%)$ & $0 / 23(0 \%)$ & $0 / 23(0 \%)$ \\
\hline $\mathbf{2}$ & 0 & 23 & 3 & 12 & 8 \\
\hline $\mathbf{3}$ & 2 & 23 & 3 & 6 & 14 \\
\hline $\mathbf{4}$ & 1 & 21 & 1 & 4 & 16 \\
\hline $\mathbf{5}$ & 0 & 20 & 0 & 2 & 18 \\
\hline $\mathbf{7}$ & 0 & 20 & 2 & 5 & 13 \\
\hline $\mathbf{1 1}$ & 2 & 18 & 2 & 9 & 7 \\
\hline $\mathbf{1 4}$ & 4 & 14 & 1 & 8 & 5 \\
\hline $\mathbf{1 8}$ & 2 & 12 & 5 & 5 & 2 \\
\hline $\mathbf{2 1}$ & 5 & 7 & 3 & 2 & 2 \\
\hline $\mathbf{2 5}$ & 2 & 5 & 2 & 2 & 0 \\
\hline $\mathbf{2 8}$ & 4 & 1 & 1 & 1 & 0 \\
\hline $\mathbf{3 5}$ & 1 & 1 & 1 & 0 & $86 / 166(51.8 \%)$ \\
\hline Total & 23 & & $24 / 166(14.45 \%)$ & $56 / 166(33.73 \%)$ & \\
\hline
\end{tabular}

Table 3: Number of different grades of fetal kicks on different days of the study.

\begin{tabular}{|lllllll|}
\hline On day & Delivered & $\mathbf{N}$ & $\begin{array}{l}\text { Grade 1 kicks } \\
\text { (diminished FM) }\end{array}$ & $\begin{array}{l}\text { Grade 2 kicks (good } \\
\text { FM) }\end{array}$ & $\begin{array}{l}\text { Grade 3 kicks } \\
\text { (very good FM) }\end{array}$ & P value \\
\hline $\mathbf{1}$ & 0 & 23 & $11 / 23(47.82 \%)$ & $12 / 23(52.17 \%)$ & $0 / 23(0 \%)$ & \\
\hline $\mathbf{2}$ & 0 & 23 & 6 & 17 & 0 \\
\hline $\mathbf{3}$ & 2 & 23 & 4 & 17 & 2 \\
\hline $\mathbf{4}$ & 1 & 21 & 1 & 16 & 4 \\
\hline $\mathbf{5}$ & 0 & 20 & 0 & 16 & 4 \\
\hline $\mathbf{7}$ & 0 & 20 & 3 & 15 & 2 \\
\hline $\mathbf{1 1}$ & 2 & 18 & 5 & 10 & 3 \\
\hline $\mathbf{1 4}$ & 4 & 14 & 3 & 10 & 1 \\
\hline $\mathbf{1 8}$ & 2 & 12 & 4 & 7 & 1 \\
\hline $\mathbf{2 1}$ & 5 & 7 & 3 & 3 & 1 & \\
\hline $\mathbf{2 5}$ & 2 & 5 & 2 & 3 & 0 & \\
\hline $\mathbf{2 8}$ & 4 & 1 & 0 & 2 & 0 & \\
\hline $\mathbf{3 5}$ & 1 & 1 & 1 & 0 & 0 & \\
\hline Total & 23 & -- & $32 / 166(19.27 \%)$ & $116 / 166(69.87 \%)$ & $18 / 166(10.84 \%)$ & $<0.01$ \\
\hline
\end{tabular}

Three women with the complaint of absent fetal movements, reported fetal movements within 1 hour after initiation of fluid challenge (Figure 3). In 3 women, fluid therapy could not improve either AFI or FM.

We noted a drop in AFI after an initial rise for variable periods in 20 women. There was a recurrent drop in AFI in every woman necessitating repeated fluid challenges. After a certain number of transfusions, the drop in AFI did not respond for the fluid challenge (Figure 1). At this stage, pregnancies were terminated with good perinatal results.

In this study, all 23 women underwent ultrasonography on day one, and all of them (100\%) had grade 1 AFI. Thereafter, ultrasound scanning was done 166 times cumulatively. Grade 1 AFI was observed on $14.45 \%$
(24/166) occasions, grade 2 AFI on $33.73 \%$ (56/166) occasions, and grade 3 AFI on $51.8 \%$ (86/166) occasions. There was a statistically significant improvement in AFI with this treatment with $p$ value of $<0.01$ (Table 2).

On day one of the study, $47.82 \%(11 / 23)$ of women reported grade 1 fetal kicks, $52.17 \%$ (12/23) of women reported grade 2 fetal kicks, and none $(0 \%)$ of the women reported grade 3 kicks (Table 2). From day two onwards, 166 fetal kick assessments were done cumulatively. Grade 1 kicks were reported on $19.27 \%$ (32/166) occasions, grade 2 kicks on $69.87 \%$ (116/166) occasions, and grade 3 kicks on $10.84 \%(18 / 166)$ occasions. There was a statistically significant improvement in the quality of fetal kicks with this treatment with $\mathrm{p}$ value of $<0.01$ (Table 3 ). 
The change of trend in fetal kick grades in selected cases is shown in Figure 2.

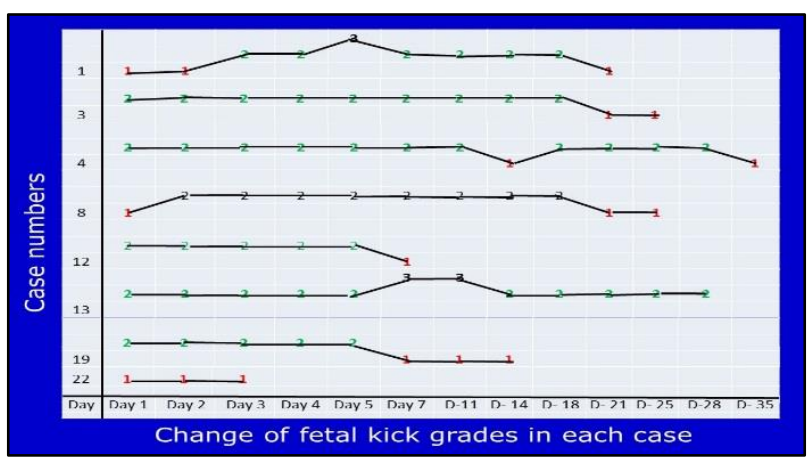

Figure 2: The trend of change in fetal kick grades in select cases of the study.

Occasional feeble kicks or no kicks, Grade 1 (Diminished FM); Less powerful kicks, grade 2 (good FM); brisk and powerful kicks, grade 3 (very good FM).

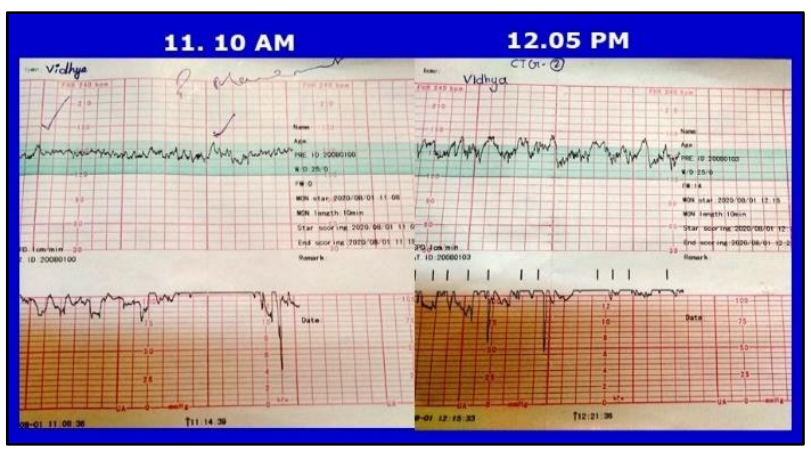

Figure 3: Woman at 33 weeks GA, case of diminished FM over 8 hours.

Interventional infusion started at $11.10 \mathrm{am}$. Within 1 hour the diminished variability was replaced by normal variability and the woman started recording FM.

The median number of days the pregnancies could be continued was (median \pm SD) $18 \pm 8.5$ days, and the mean birth weight was $2.44 \pm 0.57 \mathrm{~kg}$. The NICU admission days required ranged from 0 to 18 days. Thirteen babies (13/23, $55 \%$ ) did not require NICU admissions. All the babies survived, and the perinatal deaths were ' 0 ' in this study

\section{DISCUSSION}

Amniotic fluid is primarily made up of fetal urine. When the fetus receives inadequate nutrients and oxygen from the placenta, the blood is shunted away from the fetal kidney, resulting in reduced glomerular filtration rate and urinary output. ${ }^{13}$ Low amniotic fluid volume (oligohydramnios) due to decreased urine production by the fetal kidney reflects chronic hypo-perfusion of the fetus. Oligohydramnios occur either due to low fetal urine output or leakage of amniotic fluid from the uterus like in PROM. $^{13}$
Rapid intravenous isotonic fluid infusion within cardiovascular reserve improves blood volume and cardiac output. This results in improved tissue perfusion in all systems. Improved perfusion in the uteroplacental system results in improved fetal oxygenation, better liquor formation, and improved fetal movements. ${ }^{11}$ When plenty of oral fluids are taken, fluids continuously enter the vascular compartment from the gastrointestinal compartment. This, in turn, improves blood volume and uteroplacental perfusion. ${ }^{11}$ Intravenous L-arginine infusion causes vasodilation of uterine arteries and improves uteroplacental blood flow by increasing nitric oxide synthesis. ${ }^{14}$

In this study, before starting fluid challenge therapy, all 23 women (100\%) had AFI less than $8.00 \mathrm{~cm}$ (grade 1 AFI). AFI improved in 20 women during the course of therapy as shown in the results. After an initial raise, there was repeated drop in AFI, which required repeated fluid challenges in all women. After some variable periods, AFI started dropping down in-spite of fluid challenge. It appears that the fluid challenge could not overcome the built-up vascular resistance in uteroplacental circulation at this stage. At this stage, pregnancies were terminated with good perinatal results.

On the day one of study, 11/23 women $(47.82 \%)$ reported grade 1 fetal kicks, $12 / 23$ women $(52.17 \%)$ reported grade 2 fetal kicks, and none ( $0 \%)$ of the women reported grade 3 kicks (Table 2). After the incitation of therapy, 166 fetal kick assessments were made in this study. Grade 1 kicks (feeble kicks, diminished FM) were observed on $19.27 \%$ (32/166) occasions. Grade 2 kicks (less powerful kicks, good FM) were observed on $69.87 \%$ (116/166) occasions. Grade 3 kicks (brisk and powerful kicks, very good FM) were observed on $10.84 \%$ (18/166) occasions (Table 2). Three women with the complaint of absent fetal movements, reported fetal kicks within 1 hour after initiation of fluid challenge therapy (Figure 3).

These results show that there is a significant improvement in liquor and fetal movements with this fluid (challenge) therapy. We could continue pregnancies towards viability for a variable period of (Mean \pm SD) $18 \pm 8.5$ days. Also, we could buy some time for antenatal steroids to act to prevent neonatal functional prematurity. None of the women lost their babies in this study.

This study has some limitations. This was a preliminary interventional observational study with smaller sample size. Further RCT studies are needed to confirm our results with larger sample size.

\section{CONCLUSION}

Intravenous isotonic fluid challenge and L-arginine infusion, improves AFI and FM, and helps to prolong pregnancies towards viability. As this is a preliminary study, further studies are needed with a larger sample size, including uterine artery Doppler evaluation. 
Funding: No funding sources

Conflict of interest: None declared

Ethical approval: The study was approved by the Institutional Ethics Committee

\section{REFERENCES}

1. Phelan JP, Ahn MO, Smith CV, Rutherford SE, Anderson E. Amniotic fluid index measurements during pregnancy. J Reprod Med. 1987;32(8):601-4.

2. Magann EF, Sanderson M, Martin JN, Chauhan S. The amniotic fluid index, single deepest pocket, and two-diameter pocket in normal human pregnancy. Am J Obstet Gynecol. 2000;182(6):1581-8.

3. Prouty LA, Myers TL. Oligohydramnios sequence (Potter's syndrome): case clustering in Northeastern Tennessee. South Med J. 1987;80(5):585-92.

4. Ekin A, Gezer C, Taner CE, Ozeren M. Perinatal outcomes in pregnancies with oligohydramnios after preterm premature rupture of membranes. J Matern Fetal Neonat Med. 2015;28(16):1918-22.

5. Naveiro-Fuentes M, Puertas Prieto A, Ruíz RS, Carrillo Badillo MP, Ventoso FM, Gallo Vallejo JL. Perinatal outcomes with isolated oligohydramnios at term pregnancy. J Perinat Med. 2016;44(7):793-8.

6. Leibovitch L, Kuint J, Rosenfeld E, Schushan-Eisen I, Weissmann-Brenner A, Maayan-Metzger A. Shortterm outcome among term singleton infants with intrapartum oligohydramnios. Acta Paediatr. 2012;101(7):727-30

7. Ghosh R, Oza H, Padhiyar B. Maternal and fetal outcome in oligohydramnios: study from a tertiary care hospital, Ahmedabad, India. Int J Reprod Contracept Obstet Gynecol. 2018;7:907-10.

8. Krishna U, Bhalerao S. Placental insufficiency and fetal growth restriction. J Obstet Gynaecol India 2011;61(5):505-11.
9. Sherer DM, Dayal AK, Schwartz BM, Onyeije CI, Manning FA. Acute oligohydramnios and deteriorating fetal biophysical profile associated with severe preeclampsia. J Matern Fetal Med. 1999;8(4):193-5.

10. Van Teeffelen S, Pajkrt E, Willekes C, Van Kuijk SM, Mol BW. Transabdominal amnioinfusion for improving fetal outcomes after oligohydramnios secondary to preterm prelabour rupture of membranes before 26 weeks. Cochrane Database Systemat Rev. 2013(8).

11. Ram SH, Ram HSS, Sandhya S. Intra partum resuscitation of fetal distress with low dose isoxsuprine hydrochloride infusion with increased drop rate: An observational study. Internet J Gynaecol Obstet. 2013;17(3):1-6.

12. Hemmanur SR, Koteswaramma B, Nagashree V. A novel daily fetal movement monitoring chart to detect the fetus at risk for IUD- A case-control study. Trop J Obstet Gynaecol. 2019;36:398-402.

13. Lord M, Kole M. Amniotic Fluid Index (AFI) [Updated 2019 Feb 1]. In: StatPearls. Treasure Island (FL): StatPearls Publishing; 2020. Available from: https://www.ncbi.nlm.nih.gov/books/NBK441881/. Accessed on 11 February 2021.

14. Neri I, Mazza V, Galassi MC, Volpe A, Facchinetti F. Effects of L-arginine on utero-placental circulation in growth-retarded fetuses. Acta Obstet Gynecol Scand. 1996;75(3):208-12.

Cite this article as: Hemmanur SR, Samyuktha IS, Nagashree V. Intravenous isotonic fluid challenge, and L-arginine infusion for oligoamnios and diminished fetal movements: a preliminary study. Int J Reprod Contracept Obstet Gynecol 2021;10:2681-5. 